\title{
SOCIEDADE DE CONSUMO E MEIO AMBIENTE - AS MEDIDAS INTERNACIONAIS PARA A PROMOÇÃO DO CONSUMO SUSTENTÁVEL
}

\section{CONSUMER SOCIETY AND ENVIRONMENT - THE INTERNATIONAL MEASURES FOR THE PROMOTION OF SUSTAINABLE CONSUMPTION}

\author{
1Janaína Maria Bettes \\ ${ }^{2}$ Caroline Belletti
}

\section{RESUMO}

O capitalismo é considerado como principal responsável pelo aumento do consumo de bens, criando o chamado consumismo. Contudo, este último agrava a situação de degradação ambiental, motivo pelo qual urge a criação e a implementação de instrumentos jurídicos, políticas públicas e ações sociais voltadas a proteger o planeta e a vida que nele existe. $\mathrm{O}$ escopo deste artigo é identificar os elementos do capitalismo que impulsionam o consumismo, como surge a figura do consumo sustentável e quais são as possibilidades jurídicas, principalmente em âmbito internacional, para que os países possam contribuir para reduzir ou frear o avanço desses terríveis danos.

Palavras-Chave: Consumidor; Sustentabilidade; Meio Ambiente; Ordem Internacional; Globalização.

\begin{abstract}
Capitalism is considered as the main responsible for the increase in consumption of products, creating the so-called consumerism. However, this aggravates the situation of environmental degradation, which is why there is an urgent need for the creation and implementation of legal instruments, public policies and social actions aimed at protecting the planet and the life. The scope of this article and identify the elements of capitalism that drive consumerism, as there is a figure of sustainable consumption and what are the international legal possibilities, so that countries can contribute to reduction or to stop the advance of terrible damage.
\end{abstract}

Keywords: Consumer; Sustainability; Environment; International Order; Globalization.

\footnotetext{
${ }^{1}$ Mestranda em Direito Econômico e Socioambiental pela Pontifícia Universidade Católica do Paraná - PUC, Paraná (Brasil). E-mail: janabettes@ @otmail.com

${ }^{2}$ Mestranda em Direito Econômico e Socioambiental pela Pontifícia Universidade Católica do Paraná - PUC, Paraná (Brasil). E-mail: carolinebelletti@yahoo.com.br
} 


\section{INTRODUÇÃO}

O capitalismo, como sistema econômico predominante na atualidade, passa constantemente por momentos de crise, algumas menores e bem localizadas, outras maiores e regionais.

Entende-se que sua própria estrutura permite a eclosão desses colapsos e que o capitalismo, ao contrário de outros sistemas econômicos já vivenciados pela humanidade, possui uma capacidade impressionante de adaptação, capaz de impedir sua extinção.

Para exemplificar este fenômeno, é possível mencionar, como exemplo, a crise de 1929; a crise do petróleo da década de 1970; a crise da Bolsa de Valores de Tóquio na década de 1990 e da NASDAQ em 2000, as crises de 2008 e 2011 nos Estados Unidos da América. No momento da ocorrência de cada uma, imaginou-se que o sistema não iria suportar e viria a baixo, mas isso não aconteceu.

O fato de o capitalismo ter seus momentos de expansão e outros de retrocesso, acaba por afetar sensivelmente o desenvolvimento de países envolvidos diretamente ou não pelas crises e, por consequência, a qualidade de vida de suas populações. Isto porque os abalos financeiros, dependendo da amplitude que alcança, são capazes de gerar políticas de austeridade, com cortes de gastos, aumento de impostos e até aumento dos índices de desempregos.

Contudo, o capitalismo, em crise ou não, é responsável pelo aumento do consumo de bens pela humanidade, pois gera uma consciência coletiva de que determinados itens são indispensáveis para a sadia qualidade de vida ou capazes de atribuir status aos sujeitos que os detém ou usufruem.

Fato é que os países mais ricos são os que consomem mais, os que impulsionam a maior extração de matérias-primas da natureza para a produção de bens e geram, consequentemente, mais resíduos poluidores do meio ambiente. Frequentemente, estes mesmos países transferem as indústrias e meios de produção para países mais pobres, onde as leis trabalhistas e ambientais são mais flexíveis, de modo a agravar a situação ambiental e social desses em benefício do bem-estar daqueles.

Diante disto, o escopo deste artigo é compreender como o fenômeno do capitalismo e suas crises podem desencadear o acréscimo de consumo, transformando-o em consumismo, o qual é prejudicial à humanidade, social e ambientalmente falando, e que medidas estão sendo 
tomadas, em âmbito internacional para que os países coletivamente possam contribuir para a redução ou para frear o avanço desses terríveis danos.

\section{CRISE DO CAPITALISMO, SOCIEDADE DE CONSUMO E MEIO AMBIENTE}

A sociedade industrial começou a entrar em crise a partir da década de 1970, com a constatação de que o desenvolvimento esperado por todos não foi alcançado e que a promessa de bem-estar da civilização não se concretizou, como afirma a Heline Sivini Ferreirae (2010, p. 7-11).

No entendimento de Ulrich Beck (2002, p. 86), estamos vivendo um período chamado de segunda modernidade, em que há grandes avanços científicos, tecnológicos e até genéticos, mas marcado pela inadequada consideração das consequências que tais inovações geram, bem como pela impossibilidade de percepção dos danos pelos sentidos humanos.

Assim sendo, há uma tendência em negar os riscos que determinados avanços podem causar ou até a impossibilidade de mensurar um eventual dano futuro (BECK, 2002, p. 89), visto que muitas vezes só o tempo comprovará a existência do problema (FERREIRA, 2010, p. 22). O que gera um grande complicador, pois as medidas de segurança estão sempre defasadas em relação aos riscos, seja porque são ineficientes, seja porque são inexistentes (BECK, 2002, p. 83-84).

E é nesse cenário de inovações nucleares, modificações genéticas, e tantas outras possibilidades, que riscos cada vez maiores são gerados, em contraposição a medidas de segurança cada vez mais afastadas da sua real necessidade, que se desenvolve a teoria da sociedade de risco.

Vale destacar que esta teoria não é voltada a modificar o mundo, inclusive é taxada de pessimista. Mas tem como objetivo constatar a realidade em que estamos inseridos e despertar a necessidade de mudanças drásticas dentro da nossa sociedade, sob pena de extinção da mesma.

A globalização caracteriza-se pela quebra das fronteiras comerciais, econômicas, culturais (algumas vezes) e ambientais entre os países do mundo. Ou seja, o capitalismo, sempre em expansão, rompe os limites do Estado, e promovem uma grande revolução nos conceitos por nós conhecidos, como soberania, ética, Direito e tantos outros. 
Neste ponto é que se desenvolve a sociedade de risco global, haja vista que há uma tendência dos grandes capitais se expandirem pelo globo, em busca de novos mercados, sem que os Estados estejam preparados para limitá-los (BECK, 2002, p. 71-79).

A sociedade de risco global caracteriza-se pelo aumento desproporcional dos riscos, que já não estão situados em uma localidade pré-determinada, como um estado ou uma cidade, e se espalha por vastos territórios. São também riscos transtemporais, pois se prolongam no tempo, afetando várias gerações, e nem sempre se manifestam ou são detectados no momento de sua criação tais como o uso de celulares, que se imagina que possam causar câncer, e do uso prolongado de cigarros, que no passado não se imaginava o dano que poderia causar, tanto para quem fuma, como para quem está próximo (BECK, 2002, p. 71-79).

Como se percebe, a humanidade passa por um momento de caos, em que inúmeros são os setores que se enquadram em uma situação de crise, seja do ponto de vista político, com a crise de representatividade, da educação praticamente falida, das relações de trabalho, do Judiciário que é incapaz de responder eficientemente as demandas da sociedade, e como não poderia deixar de ser, também há a chamada crise do capital.

Primeiramente, devemos lembrar que o questionamento quanto à viabilidade estrutural do capitalismo se manifestou em alguns momentos na história da humanidade, ou seja, após a $1^{\text {a }}$ Grande Guerra e a Crise de 1929, buscou-se revisar as noções do liberalismo econômico, da autorregulação dos mercados, do padrão-ouro como sistema monetário internacional; as políticas de Keynes foram implantadas; o dólar substituiu o ouro como referência monetária internacional e os EUA entraram como líderes na organização das bases do capitalismo, ou seja, sempre com expansão (FIORI, 1999, p. 48-85).

No entanto, a crise do petróleo, na década de 1970, o aumento da inflação e do desemprego, levaram a uma nova noção de liberalismo (neoliberalismo), com a mistura de elementos do antigo liberalismo com o Estado de Bem-Estar social (PADRÓS, 2000, p. 227 266).

Na década de 1990 e até recentemente, outras crises apareceram, e sempre se questionou a estrutura do capitalismo, havendo inclusive um consenso de que ele estaria em crise.

István Mészaros dedicou-se ao estudo da chamada "crise estrutural do capital". Segundo este autor, o capitalismo é uma das formas recentes e mais bem-sucedidas do capital, 
caracterizando-se pela sujeição do trabalho ao capital (2002, p. 15-16; p. 44; 2009, p. 10) e pela produção abundante de commodities (FIRMO, 2011).

Assim, o capitalismo como o conhecido hoje, com aproximadamente 500 anos de existência, está sujeito a crises periódicas ou conjunturais, as quais são sempre superadas de alguma forma. Contudo, a crise do capital é muito mais profunda, pois é de sua natureza a expansão constante e ilimitada, capaz de destruir o que se interpuser em seu caminho (MÉSZAROS, 2009, p. 47-74). ${ }^{3}$

Karl Marx desenvolveu uma teoria, que acabou sendo admitida por outros estudiosos do assunto, tais como Michael Hardt e Antônio Negri (2001, p. 282-285); além de Ladislau Dowbor (1981, p. 22-23).

A teoria consiste basicamente na tentativa de explicar que a crise é inerente ao capitalismo, isto porque há de um lado um sistema produtivo voltado para a criação constante de lucros para os proprietários, sem atentar para as necessidades sociais; e de outro lado a anarquia da produção, gerada pela concorrência, de modo que produtos em excesso são postos no mercado (superprodução), sem que este consiga absorver aqueles devido aos baixos salários dos trabalhadores (subconsumo), acarretando a diminuição de lucros, de investimentos e de empregos (MARX, 1988).

Existiria aqui a grande contradição do capitalismo, que consiste no fato de que o proprietário dos meios de produção busca aumentar a lucratividade de seus negócios pela diminuição de salários dos trabalhadores, os quais são responsáveis pela movimentação do mercado. Assim, quanto menor for a remuneração, menor será o consumo e, portanto, menor a lucratividade do capitalista, tornando visível que este é responsável pelos problemas de sustentabilidade dos seus negócios, visto que a conduta é repetida por todos os capitalistas (MARX, 1988).

Ademais, Marx (1988) ressalta que o sistema capitalista é responsável pelo aumento da desigualdade de classes, pois tende a acumular as riquezas nas mãos de uma minoria e a proletarizar o restante da população, até o ponto que a luta de classes seria tão inevitável e devastadora, que um outro sistema produtivo seria instituído. Resumidamente, o capitalismo seria responsável pela sua própria degradação.

Assim sendo, Karl Marx já alertava os perigos do capitalismo em relação à produção exagerada de bens de consumo.

\footnotetext{
${ }^{3}$ István MÉSZAROS autor entende que a crise do capital é responsável pela crise de outras instituições, como a educação, a religião, a política e a família (2009. p.47 -74).
} 
E, ainda que ele tratasse dos problemas de um subconsumo pelos baixos salários dos trabalhadores, ele não preveria que no futuro os Estados Unidos resolveriam este problema de consumo e impulsionariam o que se chama de sociedade de consumo, marcada pelo excesso de produção de bens, a obsolescência programada destes, a publicidade como meio de convencimento de necessidades ao consumidor, as quais não existem de fato, e ao aumento dos danos socioambientais causados por este processo (PADRÓS, 2000, p. 227-266). ${ }^{4}$

O capitalismo, que parte de uma exploração sem fim da terra, precisa dela para se manter.

Rodrigo dos Santos Azevedo e José Querino Tavares Neto (2015, p.401-423) afirmar que o:

\begin{abstract}
processo de desenvolvimento deve-se incluir a preservação ambiental, que é a pedra fundamental para todos os demais aspectos, pois, é a partir da natureza que se pode produzir bens e distribuí-los à toda sociedade, ou seja, é a natureza a fonte de riqueza de todas as sociedades.
\end{abstract}

Não houve e, ainda hoje não há, uma excessiva preocupação com os danos socioambientais resultantes da industrialização excessiva, da distribuição cada vez mais desigual de renda, da preservação do meio ambiente, seja por meio da autossustentabilidade da vida humana, que pode sim ser vivida de modos diversos daqueles que estamos acostumados a ver como ideais, bem como pela reversão dos danos já causados ao meio ambiente (MORIN, 2003, p. 154-157).

O consumo sustentável é definido pelo Ministério do Meio Ambiente (MMA), pelo Ministério da Educação (MEC) e pelo Instituto Brasileiro de Defesa do Consumidor (IDEC) da seguinte forma:

O termo sociedade de consumo é uma das inúmeras tentativas de compreensão das
mudanças que vêm ocorrendo nas sociedades contemporâneas. Refere-se à
importância que o consumo tem ganhado na formação e fortalecimento das nossas
identidades e na construção das relações sociais. Assim, o nível e o estilo de
consumo se tornam a principal fonte de identidade cultural, de participaçãao na vida
coletiva, de aceitação em um grupo e de distinção com os demais. Podemos chamar
de consumismo axpansão da cultura do "ter" em detrimento da cultura do "ser". O
consumo invade diversas esferas da vida social, econômica, cultural e política. Neste
processo, os serviços públicos, as relações sociais, a natureza, o tempo e o próprio
corpo humano se transformam em mercadorias. Até mesmo a política virou uma
questão de mercado, comercializando a participação cívica e misturando valores
comerciais com valores cívicos. Isto seria uma "vitória" do consumo como um fim

\footnotetext{
${ }^{4} \mathrm{O}$ capital, à medida que ele se expande, necessita aumentar o mercado de consumo. Aqui há um interessante exemplo da atuação dos EUA após a $1^{a}$ Guerra Mundial. Pois o capitalismo desenvolvido por aquela potência teve um insight sem igual. Permitiu que classes operárias entrassem neste mercado de consumo, por meio de melhores salários que permitiam a compra de bens, como veículos, roupas, etc., produzidos a baixo custo, o que antes só era permitido às pessoas mais abastadas (PADRÓS, 2000, p.227-266).
} 
em si mesmo. O consumo passa a ser encarado, mais do que um direito ou um prazer, como um dever do cidadão. Seja como for, o consumismo, que emergiu na Europa Ocidental no século XVIII, vem se espalhando rapidamente para distintas regiões do planeta, assumindo formas diversas. O início do século XXI está sendo marcado por profundas inovações que afetam nossas experiências de consumo, como a globalização, o desenvolvimento de novas tecnologias de comunicação, o comércio através da internet, a biotecnologia, o debate ambientalista etc. Ao mesmo tempo, novos tipos de protestos e reações ao consumismo emergem, exigindo uma nova postura do consumidor (MMA; MEC; IDEC, 2005)

Isto posto, é necessária e urgente a conscientização da sociedade como um todo e a criação de meios eficazes de impedir que maiores danos socioambientais se configurem, em função de um modelo de economia malsucedido e extremamente exploratório. Políticas públicas são importantes, mas a colaboração deve surgir de todos os setores sociais, desde o grande industrial até o consumidor individual, para que os efeitos sejam realmente sentidos no planeta.

Eis que aparece aqui surge a figura do chamado consumo sustentável.

Ainda que seja deveras discutida a figura da sustentabilidade dentro do âmbito de desenvolvimento social e econômico, mudar o modo e a mentalidade de consumo, dentro de uma sociedade capitalista, parece ser uma alternativa de grande impacto para a preservação do meio ambiente, para a existência futura da humanidade e para a qualidade de vida das gerações atuais.

\section{SOCIEDADE E CONSUMO SUSTENTÁVEL}

O Instituto Brasileiro de Defesa do Consumidor (IDEC), em parceria com o Ministério do Meio Ambiente (MMA) e o Ministério da Educação (MEC), lançou pela segunda vez e de modo mais aprimorado, em 2005, um "Manual da educação para o consumo sustentável”, o qual busca conscientizar a sociedade da necessidade de serem adotadas práticas mais conscientes e responsáveis em relação ao consumo e, também, educar as crianças em idade escolar para desenvolvam qualidades de preservação do meio ambiente e levem às suas casas novas noções de sustentabilidade.

Referido documento explica os problemas resultantes da sociedade de consumo, os grandes danos ambientais e como cada pessoa pode agir em prol do meio ambiente e da sustentabilidade, de modo a evitar desperdícios, diminuir os danos ecológicos e proteger o planeta para as futuras gerações. 
Trata-se de um manual, um guia, que sugere práticas envolvendo os principais tópicos de consumo relacionados ao meio ambiente, como a água, a biodiversidade, os alimentos, os resíduos, o transporte, a energia e os meios publicitários (MMA; MEC; IDEC, 2005).

O consumo e o consumismo encontram-se intimamente ligados, sendo difícil determinar quando um termina e outro começa. Fato é que o consumo passou a ser atrelado às noções de felicidade, de desenvolvimento e de posição social, já que ter mais bens reflete prosperidade econômica e sucesso. A sociedade de consumo acaba por produzir carências e desejos de bens de maneira compulsiva e o cidadão se vê compelido a consumir cada vez mais, como se tivesse uma obrigação social e moral de assim o fazê-lo (MMA; MEC; IDEC, 2005).

"Manual da educação para o consumo sustentável" esclarece a noção de que o consumo "é o lugar onde os conflitos entre as classes, originados pela participação desigual na estrutura produtiva, ganham continuidade, através da desigualdade na distribuição e apropriação dos bens.” (MMA; MEC; IDEC, 2005)

Deste modo, o ato de consumo faz do cidadão um partícipe deste palco de conflitos em torno dos bens produzidos pela sociedade; bem como "o consumo pode se tornar uma transação politizada, na medida em que incorpora a consciência das relações de classe envolvidas nas relações de produção e promove ações coletivas na esfera pública" (MMA; MEC; IDEC, 2005).

Neste sentido, Antônio Carlos Efing e Augusto César Leite Resende explicam a relação existente entre o consumo consciente e o desenvolvimento sustentável:

Ocorre que o consumo consciente essencial ao desenvolvimento sustentável exige uma mudança de comportamento dos consumidores alienados e críticos e, para tanto, fazem-se necessárias a informação e a educação, para que os consumidores tenham ciência dos impactos negativos e positivos que sua decisão de consumo pode provocar na sociedade e no meio ambiente e dessa maneira nortear corretamente suas escolhas (EFING \& RESENDE, 2015, p. 213).

Como os padrões de consumo atuais desencadeiam uma série de problemas ambientais, que afetam o planeta como um todo, buscar um meio de desenvolver a sustentabilidade, mediante a criação de programas de educação ambiental, é um caminho que deve ser necessariamente trilhado. 
A alteração dos padrões de consumo é uma maneira da população agir politicamente para a mudança da atuação das grandes empresas e também do Estado. Para isso, a relação de consumo pode ocorrer de três diferentes formas:

a) Consumo verde - consumidor, investido do poder de escolha, busca produtos com maior qualidade e melhor preço e que não agridam o meio ambiente;

b) Consumo ético, responsável e consciente - além das questões próprias do consumo verde, aqui, o consumidor também deverá adotar um compromisso ético, social e ambientalmente responsável na hora de consumir;

c) Consumo sustentável - "além das inovações tecnológicas e das mudanças nas escolhas individuais de consumo, enfatiza ações coletivas e mudanças políticas, econômicas e institucionais para fazer com que os padrões e os níveis de consumo se tornem mais sustentáveis. Mais do que uma estratégia de ação a ser implementada pelos consumidores, consumo sustentável é uma meta a ser atingida.” (MMA; MEC; IDEC, 2005).

A partir da compreensão de o que é sociedade de consumo, de o que diferencia consumo de consumismo e de como o capitalismo é um dos responsáveis pela ocorrência e agravamento deste último, estudar-se-á agora como os organismos internacionais visam criar uma espécie de consumo mais sustentável, de modo a reduzir os danos ambientais decorrentes da exacerbação da produção de bens, extração de matérias primas e emissão de resíduos de todo o tipo no meio ambiente.

\section{INSTRUMENTOS JURÍDICOS INTERNACIONAIS DE REGULAMENTAÇÃO DO DESENVOLVIMENTO E DO CONSUMO SUSTENTÁVEIS}

A preocupação com o meio ambiente, de forma expressa, começou a ocorrer a partir da Conferência das Nações Unidas sobre o Meio Ambiente Humano, em 1972, em Estocolmo.

A Declaração oriunda deste encontro, primeiro documento jurídico a respeito do meio ambiente, estabelece princípios de proteção ambiental validos até hoje, pois destaque o papel fundamental da natureza na manutenção da vida humana.

A Declaração de Princípios de Estocolmo, com 26 itens, foi o primeiro documento jurídico a respeito do meio ambiente. Os princípios lá declarados são válidos até os dias atuais. Apesar do crescimento humano ser gigantesco, a natureza não se recuperava na mesma 
medida. Constatou-se que a natureza é finita e tem limitação; situação em que a intervenção humana deveria ser alterada para a sobrevivência (ONU, 1972).

Frente a isto, o Brasil elaborou a Lei 6.938/81, de Política Nacional de Meio Ambiente.

A partir da década de 1980 o meio ambiente é visto como tudo o que existe dentro do planeta, com a divisão em meio ambiente natural - espaço territorial do planeta, com tudo o que a natureza colocou ali dentro, como o ar, a fauna, a flora, a vida humana, etc. -, meio ambiente artificial - com tudo aquilo que é construído pelo homem -, meio ambiente cultural - lembranças de família e seus valores, criações culturais, etc., capazes de influenciar a formação humana -, e o meio ambiente do trabalho - cores claras no ambiente de trabalho, tipo de cadeiras e de mesas, horário de trabalho, combate ao assédio, entre outros (SODRÉ, 2012).

Esse meio ambiente natural é objeto de estudo do direito ambiental e das ciências ambientais. O meio ambiente artificial é objeto de estudo do direito ambiental e das ciências e profissões urbanas. Esta fase é chamada de antropocentrismo alargado ou moderado, ainda há pessoas com mentalidade antiga, mas busca-se a difusão da ideia de ecocentrismo (proteção de todos os sistemas) e de biocentrismo (proteção de todas as formas de vida) (SODRÉ, 2012).

Em 1987, a Comissão Mundial sobre o Meio Ambiente e Desenvolvimento publicou o Relatório $n^{\circ} 42 / 187$, o qual tratou pela primeira vez sobre o tema do desenvolvimento sustentável. Segundo este documento:

\footnotetext{
O desenvolvimento sustentável é o desenvolvimento que encontra as necessidades atuais sem comprometer a habilidade das futuras gerações de atender suas próprias necessidades.

Um mundo onde a pobreza e a desigualdade são endêmicas estará sempre propenso à crises ecológicas, entre outras. $\mathrm{O}$ desenvolvimento sustentável requer que as sociedades atendam às necessidades humanas tanto pelo aumento do potencial produtivo como pela garantia de oportunidades iguais para todos.

Muitos de nós vivemos além dos recursos ecológicos, por exemplo, em nossos padrões de consumo de energia. No mínimo, o desenvolvimento sustentável não deve pôr em risco os sistemas naturais que sustentam a vida na Terra: a atmosfera, as águas, os solos e os seres vivos.

Na sua essência, o desenvolvimento sustentável é um processo de mudança no qual a exploração dos recursos, o direcionamento dos investimentos, a orientação do desenvolvimento tecnológico e a mudança institucional estão em harmonia e reforçam o atual e futuro potencial para satisfazer as aspirações e necessidades humanas (ONU, 1987; 2016).
}

Contudo, em 1992, na chamada "Eco 92", realizada na cidade do Rio de Janeiro, constatou-se que os problemas naturais continuavam a existir e pioravam drasticamente. 
Assim sendo, houve a adoção da chamada "Agenda 21", documento que buscava a preservação do planeta e o desenvolvimento sustentável. Este documento detalhou vários aspectos importantes, os quais devem ser adotados para a devida proteção ambiental. Mas a este estudo, interessa o $4^{\circ}$ Capítulo, o qual trata especificamente da mudança dos padrões de consumo, ainda que outros pontos possam ser encontrados em outros capítulos esparsos (ONU, 1992).

Este Capítulo visa trabalhar a análise dos padrões insustentáveis de produção e consumo, bem como desenvolver políticas e estratégias nacionais voltadas a impulsionar mudanças nestes padrões. Assim sendo, explica-se que a degradação ambiental e a pobreza estão intimamente ligadas, e que os padrões de consumo e de produção agravam ambas as situações, como segue:

a) O item 4.3 declara que, em virtude desta relação entre a pobreza e a degradação ambiental, aquela "tem como resultado determinados tipos de pressão ambiental, as principais causas da deterioração ininterrupta do meio ambiente mundial são os padrões insustentáveis de consumo e produção, especialmente nos países industrializados.” Estes padrões de consumo alarmantes pioram a pobreza, agravam a situação das pessoas que se encontram inseridas nesta situação e, consequentemente, os desequilíbrios ambientais, os quais são praticamente inevitáveis neste contexto de desolação.

b) O item 4.4 estabelece que "como parte das medidas a serem adotadas no plano internacional para a proteção e a melhora do meio ambiente é necessário levar plenamente em conta os atuais desequilíbrios nos padrões mundiais de consumo e produção."

c) Já o item 4.5 enfatiza a atenção especial que deve ser atribuída à necessidade de recursos naturais oriunda do consumo não sustentável, além da utilização eficiente desses mesmo recursos, com o escopo de reduzir o máximo possível o seu esgotamento e a diminuir a poluição ambiental. Ainda que regiões consumam em demasia determinado bens - são estilos de vida insustentáveis das classes mais abastadas -, as necessidades fundamentais de boa parte dos consumidores não são satisfeitas - como as inadequadas condições de saúde, alimentação, habitação, etc. “A mudança dos padrões de consumo exigirá uma estratégia multifacetada centrada na demanda, no atendimento das necessidades básicas dos pobres e na redução do desperdício e do uso de recursos finitos no processo de produção" (ONU, 1992).

O Capítulo $4^{\circ}$ estabelece a necessidade de adoção de medidas capazes de promover padrões adequados de produção e de consumo, capazes de reduzir as pressões ambientais e 
atender as necessidades básicas humanas; além de desenvolver formas de implementações de padrões de consumo mais sustentáveis (ONU, 1992).

A Agenda 21 propõe a que sejam criadas novas concepções de crescimento econômico sustentável e prosperidade, “capazes de permitir melhoria nos níveis de vida por meio de modificações nos estilos de vida que sejam menos dependentes dos recursos finitos da Terra e mais harmônicos com sua capacidade produtiva" (ONU, 1992).

Os Estados, em parceria com o setor industrial privado, devem "intensificar os esforços para utilizar a energia e os recursos de modo economicamente eficaz e ambientalmente saudável” (ONU, 1992), da seguinte forma:

a) incentivando a divulgação de tecnologias saudáveis do ponto de vista ambiental que já existirem;

b) promovendo pesquisas e desenvolvendo novas tecnologias ambientalmente saudáveis;

c) apoiando os países em desenvolvimento para que façam uso adequado e eficiente dessas tecnologias e auxiliando na criação de novos meios tecnológicos apropriados para as peculiaridades de cada região;

d) fomentando a utilização ambientalmente saudável de fontes energéticas inovadoras e renováveis;

e) incitando o uso ambientalmente saudável e renovável de recursos naturais renováveis.

Ademais, cabe aos governos incentivarem o fornecimento de informações aos consumidores, de modo que estes possam fazer escolhas ambientalmente seguras para si e para os outros; bem como devem garantir que suas agências, na aquisição de produtos, também se atentem às noções de consumo sustentável (ONU, 1992).

Em 1997, a Assembleia Geral da Organização das Nações Unidas (ONU), na “Cúpula da Terra +5 ”, revisou a Agenda 21, determinando metas vinculativas aos Estados, para que houvesse efetiva diminuição de emissão de gases de efeito estufa, adequada utilização de energia e redução da pobreza para promoção do desenvolvimento sustentável (ONUBR, 2016).

Segundo informações divulgadas pela Organização das Nações Unidas no Brasil, a Cúpula Mundial sobre Desenvolvimento Sustentável, realizada em setembro de 2002, na cidade de Johanesburgo, teve com escopo avaliar as conquistas, os desafios e as novas 
situações surgidas após a Cúpula da Terra de 1992; bem como tornar concretas das metas e compromissos oriundos da Agenda 21 (ONUBR, 2016).

Outrossim, a Assembleia Geral da ONU decretou o período de 2005 a 2014 como a Década das Nações Unidas da Educação (UNESCO) para o Desenvolvimento Sustentável, para que haja uma maior conscientização da população acerca de práticas sustentáveis, beneficiando as pessoas em âmbitos privado e público, tanto no presente como no futuro (ONUBR, 2016).

Em maio de 2012, a cidade do Rio de Janeiro voltou a sediar a Conferência das Nações Unidas, mas agora em prol da Rio+20, a qual objetivava avaliar os avanços socioambientais desde a Eco 92, e verificar a necessidade de tomar novas medidas para proteção ambiental e social, bem como para impulsionar o desenvolvimento sustentável. Eis os principais itens que tratam do consumo sustentável descritos no relatório final da Conferência:

14. Nós resolvemos redobrar nossos esforços para erradicar a pobreza e a fome e assegurar que as atividades humanas respeitem os ecossistemas e os sistemas de suporte à vida da Terra. Precisamos tornar o desenvolvimento sustentável a norma geral em todos os aspectos de nossas vidas. Nós reconhecemos a responsabilidade particularmente importante de nutrir padrões de desenvolvimento sustentável e de consumo e produção sustentáveis.

(...)

26.Nós vemos a economia verde como um meio para obter o desenvolvimento sustentável, que precisa continuar sendo nossa meta geral. Nós reconhecemos que a economia verde no contexto do desenvolvimento sustentável e da erradicação da pobreza deve proteger e melhorar a base de recursos naturais, ampliar a eficiência dos recursos, promover padrões de consumo e produção sustentáveis, e guiar o mundo na direção do desenvolvimento com baixo consumo de carbono.

(...)

97. Nós concordamos em estabelecer uma Estrutura de Programas de 10 Anos para o consumo e produção sustentáveis (SCP) como parte de um pacto global sobre o consumo e produção sustentáveis, baseado no texto elaborado nas negociações na Comissão da ONU sobre o Desenvolvimento Sustentável em sua $19^{a}$ sessão.

(...)

107. Nós propomos que os Objetivos de Desenvolvimento Sustentável possam incluir os padrões de consumo e produção sustentáveis assim como áreas prioritárias como os oceanos; a segurança alimentar e a agricultura sustentável; a energia sustentável para todos; acesso e eficiência de água; cidades sustentáveis; trabalhos verdes, empregos decentes e inclusão social; e redução de riscos e a resistência a desastres (ONU, 2012).

Diante disto, fica evidente a necessidade de se alterarem os padrões e as concepções que a humanidade ainda adota em relação ao consumo, à riqueza, ao desenvolvimento e a consciência coletiva. A ONU propõe várias formas de proteção do meio ambiente, para que a humanidade não se extinga num futuro próximo. Contudo, é preciso que Estados, produtores, comerciantes e consumidores ajam 


\section{CONCLUSÃO}

Tratar da relação existente entre o sistema capitalista, o consumo e o consumismo, e a preservação do meio ambiente, é tema de elevada complexidade e necessidade nos dias de hoje, pois estão em jogo muitos interesses e estruturas de poder.

De um lado, todos merecem ter uma vida mais confortável, mas, de outro, quais são os limites do conforto que uma pessoa precisa para viver e aquilo que chega ao patamar da futilidade, da ostentação? Qual é o preço ambiental desse excesso de comodidades dos tempos modernos? Qual é o impacto das posturas consumistas dos indivíduos e entes mais abastados na vida daqueles que não têm possibilidade de terem satisfeitas suas condições mínimas de dignidade, como o acesso à água potável, à alimentação saudável e à higiene?

A humanidade chega a um ponto em que não é possível mais fazer vistas grossas para os problemas ambientais decorrentes do consumismo, pois todos, sem exceção, estão sendo prejudicados, pelo aquecimento global, pelo derretimento das calotas polares, pelo aumento nos níveis dos mares, pela polução do ar, das águas e do solo, enfim pela impossibilidade de o ecossistema global se recuperar da degradação que lhe é imposta todos os momentos do dia.

Assim, a criação de medidas voltadas à conscientização dos indivíduos, das instituições e dos governos da necessidade urgente de adoção de atos de desenvolvimento e de consumo sustentáveis, parece ser o primeiro passo importante para salvar o planeta e toda a vida que há nele. Referidas medidas desenvolvidas primeiramente em âmbito internacional e, posteriormente, dentro do ordenamento jurídico de cada país, possibilitaram a utilização de políticas públicas voltadas ao reflorestamento, ao fim da obsolescência programada de produtos, à reciclagem, à promoção de meios alternativos de transporte, de energia e de alimentação (tanto na agricultura, na pecuária, como no combate ao consumo de alimentos processados), entre outros temas.

O Brasil, à luz dos instrumentos jurídicos internacionais mencionados no terceiro ponto deste estudo, já possui, ainda que timidamente, uma série de normas jurídicas, políticas públicas e atividades de entidades não-governamentais voltadas à conscientização e à efetivação de ações de desenvolvimento e de consumo sustentáveis socioambientalmente.

A título de exemplificação, há dispositivos na Constituição da República para a proteção do consumidor, o desenvolvimento do país, a proteção ambiental e a possibilidade de 
tratamento diferenciados para produtos e serviços dependendo do impacto ambiental que tiverem. O Código de Defesa do Consumidor declara abusivas a publicidade e as cláusulas contratuais que violem de alguma forma valores e normas ambientais, respectivamente.

A Lei ${ }^{\circ}$ 9.605/95 trata de crimes ambientais e de Unidades de Conservação de Uso Sustentável e Reservas de Desenvolvimento Sustentável; a Lei $\mathrm{n}^{\circ}$ 12.305, institui a Política Nacional de Resíduos Sólidos, além de outros tantos exemplos de normas.

Contudo, merece destaque a Lei ${ }^{\circ} 13.186 / 2015$, que institui a Política de Educação para o Consumo Sustentável, representando um verdadeiro avanço nacional sobre o assunto, pois tem por escopo estimular a adoção de práticas de consumo e de técnicas de produção ecologicamente sustentáveis.

Diante disso, fica evidente que a importância do tema ora abortado neste estudo e que medidas mais efetivas ainda precisam ser realizadas por todas as esferas da sociedade e por todo o planeta, para que sejam vislumbradas mudanças reais na preservação do meio ambiente e da vida, e não apenas alterações nos aspectos econômico e desenvolvimentista.

\section{REFERÊNCIAS}

AZEVEDO, Rodrigo dos Santos; TAVARES NETO, José Querino. Economia Sustentável a partir da Sociedade de Consumo: Desafios ao Desenvolvimento Brasileiro. 2015, p. 401-423. Disponível em: http://www.conpedi.org.br/publicacoes/c178h0tg/8uix05yq/8cq043mhW6UvaBO2.pdf. Acesso em: 05 set 2016.

BECK, Ulrich. La sociedad del riesgo global. España: Siglo Veintiuno, 2002.

DOWBOR, Ladislau. Introdução teórica à crise: salários e lucros na divisão internacional do trabalho. São Paulo: Brasiliense, 1981.

EFING, Antônio Carlos; RESENDE, Augusto César Leite. Educação para o consumo consciente: um dever do Estado. RDA - Revista de Direito Administrativo, vol. 269, Rio de Janeiro, mai/ago 2015, p. 197-224.

FERREIRA, Heline Sivini. Desvendando os organismos transgênicos: as interferências da sociedade de risco no Estado de Direito Ambiental. Rio de Janeiro: Forense Universitária, 2010.

FIORI, José Luís. Estado, moedas e desenvolvimento. In: FIORI, José Luís (org.). Estado e moedas no desenvolvimento das nações. Petrópolis: Vozes, 1999. 
FIRMO. Érico. O capital além do capitalismo. O Povo. Disponível em: http://www.opovo.com.br/app/opovo/paginasazuis/2011/06/27/noticiasjornalpaginasazuis,226 0559/o-capital-alem-do-capitalismo.shtml Acesso em: 14 jun 2016.

HARDT, Michael; NEGRI, Antonio. Império. 2a ed. Rio de Janeiro: Record, 2001.

MARX, Karl. As crises econômicas do capitalismo. São Paulo: Editora Acadêmica, 1988.

MÉSZÁROS, István. A crise estrutural do capital. São Paulo: Boitempo, 2009.

MÉSZÁROS, István. Para além do capital: ruma a uma teoria da transição. São Paulo: Boitempo, 2002.

MMA; MEC; IDEC. Consumo Sustentável: Manual de educação. Brasília, 2005. Disponível

em: http://www.idec.org.br/uploads/publicacoes/publicacoes/Manual_completo.pdf Acesso em 14 jun 2016.

MORIN, Edgar; KERN. Anne-Brigitte. Terra pátria. Porto Alegre: Sulina, 2003.

ONU. Agenda 21 da Conferência das Nações Unidas sobre Meio Ambiente e Desenvolvimento. 1992. Disponível em: http://www.mma.gov.br/responsabilidadesocioambiental/agenda-21/agenda-21-global. Acesso em: 15 jun 2016.

ONU. Declaração da Conferência das Nações Unidas sobre o Meio Ambiente Humano -1972. http://www.apambiente.pt/_zdata/Politicas/DesenvolvimentoSustentavel/1972_Declaracao_Es tocolmo.pdf Acesso em 15 jun 2016.

ONU. Relatório da Comissão Mundial sobre Meio Ambiente e Desenvolvimento $\mathbf{n}^{\circ}$ 42/187. 1987. Disponível em: http://www.un.org/documents/ga/res/42/ares42-187.htm e https://nacoesunidas.org/acao/meio-ambiente/ . Acesso em: 15 jun 2016.

ONU. Rio +20. Conferência das Nações Unidas sobre Desenvolvimento Sustentável. O futuro que queremos. 2012. Disponível em: http://www.rio20.gov.br/documentos/documentos-da-conferencia/esbocozero/at_download/esboco-zero.pdf. Acesso em: 15 jun 2016.

ONUBR. A ONU e o meio ambiente. 2016. Disponível em: https://nacoesunidas.org/acao/meio-ambiente/. Acesso em: 15 jun 2016.

PADRÓS, Enrique Serra. Capitalismo, prosperidade e Estado de bem estar social. In.: REIS FILHO, Daniel Aarão; FERREIRA, Jorge; ZENHA, Celeste (orgs). O século XX. Rio de Janeiro: Civilização Brasileira, 2000.

SODRÉ, Ângelo. O Conceito e as Classificações de Meio Ambiente. Universo Jurídico, Juiz de Fora, ano XI, 30 de nov. de 2012. Disponivel em: http://uj.novaprolink.com.br/doutrina/8834/o_conceito_e_as_classificacoes_de_meio_ambien te. Acesso em: 15 de jun. de 2016. 